\title{
Pengembangan Subject Specific Pedagogy (SSP) Tematik Berbasis Local Wisdom Untuk Membangun Karakter Hormat dan Kepedulian Siswa SD
}

\author{
Amaliyah Ulfah \\ amaliyah.ulfah@pgsd.uad.ac.id \\ Universitas Ahmad Dahlan
}

\begin{abstract}
The Development of Thematic Subject Specific Pedagogy Based on Local Wisdom to Build Respect and Care of the Second Grade Students
\end{abstract}

\begin{abstract}
This study aims at generating possible thematic Subject Specific Pedagogy (SSP) based on local wisdom and examining the results teachers and students perception on the pedagogical approach developed in the preliminary field testing. Drawing upon the notion of research and development by Borg \& Gall, this research was conducted through different stages involving information gathering, planning, developing preliminary product, preliminary field testing, and revising. The subjects were a small group of second grade students of $S D$ Muhammadiyah Bodon and SD Muhammadiyah Sidoarum Yogyakarta. Each consists of 10 students. The data gathering instrument consists of product validation, character observation sheets, and teacher assessment sheets. The data gathering instrument consists of product validation tool, character observation sheets, and teachers' assessment sheets. The SSP product generated in this study consists of lesson plans, teaching materials, worksheets, and expert perception. According to the experts of media, materials, and evaluation, the SSP product is in good categories. First grade teachers result a good score to the syllabus and lesson plans, while the worksheets and evaluation are in very good category. The results from the students responses to the textbooks is 78 , which is in very good category, while the students worksheets score 71 which includes in excellent category. Therefore, the developed thematic SSP based on local wisdom can be declared appropriate for use in learning.
\end{abstract}

Keywords: Subject Specific Pedagogy, thematic, character, local wisdom

Received date: 24 Juli $2017 \quad$ Article Info $\quad$ Revised date: 01 Oktober $2017 \quad$ Accepted date: 19 Desember 2017

\section{PENDAHULUAN}

Masalah pendidikan di Indonesia muncul dari segala aspek baik internal maupun eksternal. Dilihat dari faktor internal, sistem pendidikan yang diterapkan di sekolah saat ini masih banyak menekankan pada hafalan yang tidak diikuti dengan pemahaman yang dapat diterapkan siswa ketika berhadapan dengan situasi nyata dalam kehidupannya, akibatnya pembelajaran kurang membekas pada diri siswa (Abidinsyah \& Budimansyah 2012: 2). Tolak ukur keberhasilan pendidikan juga lebih ditekankan pada kemampuan siswa menjawab soal-soal ujian dan nilai, bukan pada terwujudnya karakter dan moral anak. Sedangkan pengaruh faktor dari luar seperti kemudahan akses internet, game online, tayangan televisi yang kurang mendidik, munculnya group musik dari luar juga membuat siswa semakin mudah meninggalkan budaya dan nilai-nilai luhur bangsa. Pada akhirnya saat ini kita sering menjumpai banyaknya anak-anak yang kurang bisa menghormati orang yang lebih tua, berperilaku menyimpang, dan tidak mengenal budaya sendiri. 
Karakter yang kuat sangat penting untuk membangun peradaban bangsa. Oleh karena itu karakter perlu dibentuk dan sebaiknya dilakukan sedini mungkin. Menurut Freud (Muslich, 2011:35) kegagalan penanaman kepribadian yang baik di usia dini akan membentuk pribadi yang bermasalah di masa dewasanya. Banyak pakar mengatakan usia dini merupakan masa kritis bagi pembentukan karakter seseorang. Apalagi anak usia dini termasuk dalam golden age, tahap ini merupakan tahap terbaik perkembangan fisik dan otak anak. Sehingga dalam hal ini peran orang tualah yang sangat diperlukan dalam membentuk karakter anak-anaknya.

Keberhasilan pendidikan karakter tidak bisa dilakukan oleh salah satu pihak. Selain keluarga, factor lain yang juga berpengaruh yaitu lingkungan sekolah. Battistich (2008:82) menjelaskan "character education as the deliberate use of all dimensions of school life to foster optimal character development". Pendidikan karakter sebagai upaya sengaja menggunakan semua dimensi kehidupan sekolah untuk mendorong pengembangan karakter secara optimal. Pendidikan karakter dapat diwujudkan dengan melibatkan seluruh komponen yang ada di sekolah seperti isi kurikulum, proses pembelajaran, kualitas hubungan, penanganan mata pelajaran, pelaksanaan aktiviats ko-kurikuler, dan etos seluruh lingkungan sekolah. Sekolah dasar sebagai lembaga pendidikan formal pertama memang memiliki peran strategis dalam penanaman karakter dan budaya siswa. Banyak upaya yang telah dilakukan pemerintah untuk menghidupkan kembali pendidikan karakter, salah satunya yaitu dengan mengubah kurikulum KTSP menjadi kurikulum 2013. Penggunaan Kurikulum 2013 sendiri dianggap mampu menciptakan generasi yang lebih unggul dan bermoral karena pembelajarannya dirancang lebih aktif, bermakna, dan kompetensi-kompetensi yang disajikan antara pengetahuan, keterampilan, dan sikap juga seimbang.

Perbedaan Kurikulum 2013 dengan kurikulum sebelumnya yaitu adanya buku guru dan buku siswa. Buku guru merupakan pedoman bagi guru dalam melaksanakan pembelajaran dengan pendekatan tematik. Buku guru memuat kompetensi, materi-materi, rencana pelaksanaan pembelajaran (RPP), hingga evaluasinya. Kurikulum 2013 belum begitu lama dilaksanakan, namun sudah banyak sekali dijumpai kendala di lapangan. Seperti penelitian yang dilakukan Krissandi dan Rusmawan (2015:457) tentang kendala-kendala yang dialami guru SD dalam implementasi kurikulum 2013. Ada 5 hal yang menjadi kendala dalam implementasi kurikulum 2013 yaitu berasal dari pemerintah, institusi, guru, orang tua, dan siswa. Kendala dari pemerintah meliputi pendistribusian buku, pedoman penilaian yang kurang jelas, administrasi guru, alokasi waktu, sosialisasi, pelaksanaan pembelajaran tematik, panduan pelaksanaan kurikulum, dan kegiatan pembelajaran dalam buku siswa. Kendala dari institusi meliputi sarana dan prasarana, serta rotasi guru baik vertikal dan horisontal. Kendala dari guru meliputi pembuatan media pembelajaran, pemahaman guru, pemaduan antarmuatan pelajaran dalam pembelajaran tematik, dan penguasan teknologi informasi. Sedangkan kendala dari orang tua dan siswa meliputi rapor dan sulitnya beradaptasi dengan pembelajaran tematik.

Hal ini diperkuat dengan kondisi nyata di lapangan, berdasarkan hasil observasi di beberapa sekolah dasar di Yogyakarta diperoleh beberapa informasi sebagai berikut: 1) banyak guru kelas yang belum bisa menerapkan pembelajaran tematik sehingga pelaksanaannya masing terpisah-pisah antar mata pelajaran, 2), beberapa guru kelas menjumpai materi ajar dalam buku siswa ada yang keliru dan kurang sesuai, 3) banyak guru 
Pengembangan Subject Specific Pedagogy (SSP) Tematik Berbasis Local Wisdom Untuk Membangun Karakter Hormat dan Kepedulian Siswa SD (Amaliyah Ulfah)

merasa kesulitan dalam melakukan penilaian K13, 4) guru kesulitan mengatur alokasi waktu dalam pembelajaran, sehingga orientasi guru lebih banyak untuk menyelesaikan materi. SD Muhammadiyah Bodon merupakan salah satu SD yang sudah menerapkan kurikulum 2013. Berdasarkan hasil wawancara dengan guru kelas II diperoleh informasi guru sudah menggunakan buku guru dan buku siswa dalam pembelajaran, akan tetapi isi materi dalam buku ada yang kurang sesuai dengan kondisi di lapangan. Selain itu guru juga sudah menyusun RPP ulang, namun dalam proses pembelajarannya pendidikan karakter belum begitu tampak. Pembelajaran tematik justru lebih berorientasi pada terselesaikannya materi.

Berdasarkan salah satu hasil penelitian yang dilakukan oleh Darmiyati Zuchdi, dkk. (2014: 1) juga menjelaskan bahwa perencanaan pendidikan karakter di sekolah-sekolah Kota Yogyakarta sudah dilakukan dengan cukup baik. Namun, berdasarkan analisis RPP yang dibuat oleh guru, ada beberapa RPP yang belum mengandung nilai-nilai target yang akan dikembangkan dalam pembelajaran. Banyak guru yang kemungkinan mengalami kesulitan membuat RPP bermuatan pendidikan.

Sedangkan berdasarkan hasil observasi terhadap siswa kelas II ditemukan masih banyak siswa yang kurang bisa mengimplementasikan sikap positif dalam lingkungan sekolah. Contohnya antar siswa masih suka saling mengejek, sebagian besar siswa masih menggunakan Bahasa Jawa kasar ketika berbicara dengan guru, guru masih sering mengingatkan siswa untuk mengucapkan terima kasih, dan tolong, serta makan sambil duduk. Siswa juga masih sering berbicara atau bermain dan bercanda dengan teman yang tidak berhubungan dengan materi pelajaran, serta masih ada siswa yang terlihat siswa naik di kursi ketika proses belajar berlangsung. Kondisi ruangan ketika pembelajaran terlihat tidak tertata dengan rapi karena sikap siswa yang kurang tertib.

Berdasarkan pengamatan terhadap peserta didik diperoleh gambaran karakter yang mendesak perlu dibangun yaitu karakter hormat dan kepedulian. Karakter hormat terkait masih banyaknya siswa yang belum bisa menunjukkan rasa hormat, belum menghargai guru, maupun teman lain. Sedangkan kepedulian berkaitan masih kurangnya sikap peserta didik yang menunjukkan rasa peduli terhadap teman, terhadap kebersihan maupun kerapian lingkungan.

Untuk mengintegrasikan nilai-nilai tersebut dalam pembelajaran, diperlukan sebuah perangkat pembelajaran komprehensif seperti Subject Specific Pedagogy (SSP). Menurut pedoman pembukaan program PPG Ristekdikti (2017: 9) SSP diartikan sebagai pengemasan bidang studi menjadi perangkat pembelajaran yang komprehensif dan mendidik. Komprehensif menggambarkan perencanaan pembelajaran yang disusun runtut dan padu dimulai dari analisis kompetensi dasar dalam silabus sampai lembar penilaiannya. Sedangkan mendidik berarti pembelajaran perlu dirancang untuk membangun sikap dan karakter peserta didik.

Agar pengintegrasian nilai dalam perangkat pembelajaran mudah diterima siswa, nilai yang dapat digunakan yaitu nilai-nilai yang bersumber dari kearifan lokal (local wisdom) masing-masing daerah. Menurut Wagiran (2012: 330) menggali nilai-nilai kearifan lokal merupakan upaya strategis dalam membangun karakter bangsa di era global. Pendidikan berbasis kearifan lokal adalah pendidikan yang mengajarkan peserta didik untuk selalu lekat dengan situasi konkret yang mereka hadapi. 
Berdasarkan uraian di atas, perlu dikembangkan produk SSP tematik berbasis local wisdom untuk membangun karakter hormat dan kepedulian siswa. Penelitian ini bertujuan menghasilkan dan mengetahui kelayakan SSP tematik berbasis local wisdom untuk membangun karakter hormat dan kepedulian bagi siswa sekolah dasar kelas II. Adapun spesifikasi produk yang dikembangkan yaitu perangkat pembelajaran yang terdiri dari yaitu 1) silabus, 2) RPP, 3) bahan ajar, 4) Lembar Kerja Siswa (LKS) dan, 5) lembar penilaian.

\section{KAJIAN PUSTAKA}

SSP dikenalkan pertama kali oleh Shulman sebagai PCK (Pedagogical Content Knowledge). Shulman (Yenny Anwar, dkk., 2012: 158) menjelaskan bahwa seorang guru profesional harus memiliki pengetahuan dan kemampuan Pedagogical Content Knowledge (PCK) yang baik. Sebagai agen pengubah seyogianya para guru terus mengembangkan proses mengajarnya di kelas dan calon guru terus melatih kemampuannya dalam merancang pembelajaran, salah satunya dengan memahami PCK.

Menurut Mishra \& Koehler dalam Resbiantoro (2016: 154) PCK mencakup kegiatan inti pengajaran, pembelajaran, kurikulum, penilaian, dan pelaporan yaitu yang mendukung kegiatan belajar siswa dan hubungan antara kurikulum, penilaian, dan pedagogi. Van Driel, Verloop, \& de Vos (1998: 674) juga menjelaskan PCK sebagai berikut.

Pedagogical content knowledge is considered to be craft knowledge, defined as integrated knowledge which represents the teachers' accumulated wisdom with respect to their teaching practice. As craft knowledge guides the teachers' actions in practice, it encompasses teachers' knowledge and beliefs with respect to various aspects such as pedagogy, students, subject matter, and the curriculum.

PCK dianggap sebagai seni pengetahuan, didefinisikan sebagai pengetahuan terpadu yang mewakili kebijaksanaan guru sehubungan dengan praktek mengajar mereka. Secara umum $P C K$ menitikberatkan pada kemampuan dan keahlian guru untuk menciptakan pembelajaran yang efektif dan bermakna sesuai dengan karakteristik materi yang akan diajarkan.

Menurut Permendiknas No. 8 Tahun 2009 Pasal 1 Ayat 6 Subject Specific Pedagogy atau SSP adalah pengemasan materi bidang studi menjadi perangkat pembelajaran yang komprehensif, mencakup standar kompetensi, materi, strategi, metoda, media, dan evaluasi. Sedangkan sebagai produk, SSP ditampilkan dalam bentuk pengemasan bidang studi menjadi perangkat pembelajaran yang komprehensif meliputi silabus, RPP, Bahan Ajar, LKS, dan instrument penilaian (Paimun dan Masruri, 2014: 196). Sedangkan Margo dalam Apriani dan Nur Wangid (2015: 14) menjelaskan "Subject-specific Pedagogy is based on the "how to learn something'. It not only what we learn, it is also why and how we think it.". Jadi SSP bukan sekedar bagaimana belajar sesuatu (kognitif) melainkan mengapa dan bagaimana belajar tentang sesuatu agar berguna bagi diri sendiri maupun orang lain (afektif).

Pembelajaran tematik sendiri merupakan model pembelajaran terpadu yang menggunakan tema untuk mengaitkan beberapa mata pelajaran sehingga dapat memberikan pengalaman bermakna kepada siswa (Sukini, 2012: 61). Salah satu tujuan dalam pembelajaran tematik yaitu terwujudnya kompetensi ranah afektif atau sikap siswa. Sukini juga menjelaskan beberapa karakterisik pembelajaran tematik yaitu 1) berpusat pada siswa 
Pengembangan Subject Specific Pedagogy (SSP) Tematik Berbasis Local Wisdom Untuk Membangun Karakter Hormat dan Kepedulian Siswa SD (Amaliyah Ulfah)

(student centered), 2) memberikan pengalaman langsung, 3) pemisahan mata pelajaran tidak begitu jelas, 4) menyajikan konsep dari berbagai mata pelajaran dalam suatu proses pembelajaran, 5) bersifat luwes/fleksibel, 6) hasil pembelajaran sesuai dengan minat dan kebutuhan siswa.

Agar pembelajaran tematik lebih efektif, maka harus dirancang dengan baik secara mendidik melalui SSP yang menggunakan strategi-strategi, metode, media, dan prinsipprinsip tertentu yang disesuaikan dengan karakteristik siswa serta content atau isi materi yang akan diajarkan. Selain itu pembelajaran tematik juga perlu diiintegrasian dengan nilai-nilai karakter yang mudah diterima siswa. Salah satu nilai yang dapat digunakan yaitu nilai-nilai yang bersumber dari kearifan lokal (local wisdom) masing-masing daerah.

Yuliani (2013: 2) mengatakan bahwa kearifan lokal (local wisdom) adalah kebenaran yang telah mentradisi atau ajeg dalam suatu daerah. Menurut Tobroni (2011: 106) orangt tua, kampung halaman dan tanah air, bahasa, agama, budaya, sistem sosial, bangsa dan negara adalah sumber kearifan lokal dan harus dijadikan dasar dalam pembentukan kepribadian anak. Berbagai macam local wisdom tersebut merupakan potensi pengembangan pendidikan berbasis kearifan lokal. Itulah sebabnya, dunia pendidikan perlu segera merancang, menentukan model yang paling tepat untuk melakukan penyemaian kearifan lokal.

Menurut Wagiran (2012: 330) menggali nilai-nilai kearifan lokal merupakan upaya strategis dalam membangun karakter bangsa di era global. Pendidikan berbasis kearifan lokal adalah pendidikan yang mengajarkan peserta didik untuk selalu lekat dengan situasi konkret yang mereka hadapi. Kearifan lokal merupakan modal pembentukan karakter luhur. Karakter luhur adalah watak bangsa yang senantiasa bertindak dengan penuh kesadaran dan pengendalian diri. Pijaran kearifan lokal selalu berpusar pada upaya menanggalkan hawa nafsu, meminimalisir keinginan, dan menyesuaikan dengan empan papan.

\section{METODE PENELITIAN}

Jenis penelitian yang digunakan adalah penelitian pengembangan yang dikembangkan oleh Borg \& Gall atau yang dikenal dengan istilah Research and Development. Tahapan penelitian menurut Borg \& Gall dalam Sugiyono (2015: 35) yaitu 1) Penelitian dan pengumpulan informasi, 2) Perencanaan, 3) Pengembangan produk awal, 4) Uji coba lapangan tahap awal, 5) Revisi produk hasil uji coba, 6) Uji coba lapangan utama, 7) Revisi produk uji coba lapangan utama, 8) Uji lapangan operasional, 9) Revisi produk akhir, 10) Desiminasi. Prosedur pengembangan yang dilakukan dalam penelitian hanya sampai tahapan kelima yaitu tahap revisi produk uji coba lapangan awal.

Uji coba yang dilakukan dalam penelitian yaitu uji coba lapangan tahap awal. Subjek uji coba produk adalah guru dan siswa kelas 2 SD Muhammadiyah Sidoarum sebanyak 10 anak. Instrumen pengumpulan data dalam penelitian ini berupa lembar validasi (silabus, RPP, Bahan Ajar, LKS, dan Perangkat Penilaian), lembar penilaian guru, dan angket untuk siswa. Teknik analisis data dilakukan dengan langkah-langkah sebagai berikut: 1) Mentabulasi semua data yang diperoleh dari para validator, 2) Melakukan konversi skor total actual menjadi data kuantitatif skala lima menurut Sukardjo (2005: 55). 
Tabel 1.

Konversi Skor Menjadi Skala Lima

\begin{tabular}{lccc}
\hline No & Skor Siswa & Nilai & Kriteria \\
\hline 1 & $\mathrm{X}>\mathrm{Mi}+1,8 \mathrm{SB}_{\mathrm{i}}$ & $\mathrm{A}$ & Sangat baik \\
2 & $\mathrm{Mi}+0,6 \mathrm{SB}_{\mathrm{i}}<\mathrm{X} \leq \mathrm{Mi}+1,8 \mathrm{Sbi}$ & $\mathrm{B}$ & Baik \\
3 & $\mathrm{Mi}-0,6 \mathrm{SB}_{\mathrm{i}}<\mathrm{X} \leq \mathrm{Mi}+0,6 \mathrm{Sbi}$ & $\mathrm{C}$ & Cukup baik \\
4 & $\mathrm{Mi}-1,8 \mathrm{SB}_{\mathrm{i}}<\mathrm{X} \leq \mathrm{Mi}-0,6 \mathrm{Sbi}$ & $\mathrm{D}$ & Kurang baik \\
5 & $\mathrm{X} \leq \mathrm{Mi}-1,8 \mathrm{SB}_{\mathrm{i}}$ & $\mathrm{E}$ & Sangat kurang baik \\
Keterangan: & & & \\
$\mathrm{X}=$ Skor aktual & & \\
$\mathrm{Mi}$ & $=$ Mean ideal $\left(1 / 2\left(\mathrm{X}_{\text {mak }}+\mathrm{X}_{\min }\right)\right.$ & & \\
$\mathrm{Sbi}$ & $=$ Simpangan baku ideal $=1 / 6\left(\mathrm{X}_{\text {mak }}-\mathrm{X}_{\text {min }}\right)$ & &
\end{tabular}

\section{HASIL PENELITIAN DAN PEMBAHASAN}

Produk SSP yang dikembangkan berupa Silabus, RPP, Buku ajar, LKS, dan Perangkat penilaian berbasis local wisdom bagi siswa sekolah dasar kelas 2 . Tema yang dikembangkan yaitu Hidup Rukun dengan Teman Bermain yang terdiri dari 6 pembelajaran. Untuk mengetahui kelayakan produk yang dikembangkan dilakukan validasi oleh ahli (expert judgment) yaitu ahli kurikulum ahli media, ahli materi, ahli evaluasi pembelajaran, dan ahli bahasa jawa. Hasil validasi SSP dapat dilihat pada Tabel 2.

Tabel 2.

Hasil Validasi SSP Oleh Ahli

\begin{tabular}{|c|c|c|c|c|c|c|}
\hline \multirow[b]{2}{*}{ No } & \multirow[b]{2}{*}{ Validator } & \multicolumn{5}{|c|}{ Produk SSP berbasis Local Wisdom } \\
\hline & & Silabus & RPP & $\begin{array}{c}\text { Buku } \\
\text { Ajar }\end{array}$ & LKS & $\begin{array}{l}\text { Perangka } \\
\text { Penilaian }\end{array}$ \\
\hline 1 & Ahli Kurikulum & $\begin{array}{c}56 \\
\text { (Baik) }\end{array}$ & $\begin{array}{c}109 \\
\text { (Baik) }\end{array}$ & - & - & 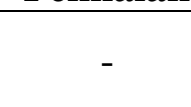 \\
\hline 2 & Ahli Media & - & - & $\begin{array}{c}53 \\
\text { (Baik) }\end{array}$ & $\begin{array}{c}51 \\
\text { (Baik) }\end{array}$ & - \\
\hline 3 & Ahli Materi & - & - & $\begin{array}{c}62 \\
\text { (Baik) }\end{array}$ & $\begin{array}{c}60 \\
\text { (Baik) }\end{array}$ & - \\
\hline 4 & Ahli Evaluasi Pembelajaran & - & - & - & - & $\begin{array}{c}52 \\
\text { (Baik) }\end{array}$ \\
\hline
\end{tabular}

Berdasarkan beberapa Tabel yang sudah disajikan, dapat diketahui skor hasil validasi mendapatkan kategori baik dan sangat baik. Adapun rinciannya yaitu silabus menurut ahli kurikulum mendapat kategori baik, RPP berkategori baik, Buku Ajar menurut ahli media dan materi berkategori baik, LKS menurut ahli media dan materi berkategori baik, dan perangkat penilaian berkategori sangat baik.

Untuk melihat kesesuaian bahasa yang digunakan dalam buku ajar, juga dilakukan validasi oleh ahli bahasa jawa. Berikut hasil telaah buku ajar oleh ahli bahasa jawa. 
Pengembangan Subject Specific Pedagogy (SSP) Tematik Berbasis Local Wisdom Untuk Membangun Karakter Hormat dan Kepedulian Siswa SD (Amaliyah Ulfah)

Tabel 3.

Hasil Validasi Ahli Bahasa Jawa Terhadap Buku Ajar Kelas 2

\begin{tabular}{ll}
\hline \multicolumn{1}{c}{ Sebelum } & \multicolumn{1}{c}{ Sesudah validasi } \\
\hline Lirik lagu jaranan kurang & Setelah lirik ke empat mendapat \\
lengkap & tambahan " siring-sring turut lurung" \\
"jeg-jeg gedebukjedher" & "prok-prok gedebuk jedher". \\
Gundul-Gundul Pacul & Gundhul-Gundhul Pacul \\
enggrang & egrang \\
\hline
\end{tabular}

Saran-saran yang diperoleh dari ahli digunakan untuk memperbaiki produk SSP yang akan digunakan pada uji coba lapangan awal. Pada tanggal 26 September 2016 dilakukan uji coba lapangan awal di SD Muhammadiyah Sidoarum. Tujuan dilaksanakannya uji coba ini yaitu untuk mengetahui penilaian SSP menurut guru dan siswa. Jumlah subjek coba yang digunakan sebanyak 10 siswa. Hasil penilaian guru maupun siswa dapat dilihat pada Tabel 4 dan Tabel 5.

Tabel 4.

Penilaian SSP oleh Guru Kelas 2 pada Uji Coba Lapangan Awal

\begin{tabular}{clccc}
\hline No. & \multicolumn{1}{c}{ Produk } & Skor aktual & Skor maksimal & Kategori \\
\hline 1 & Silabus & 62 & 70 & Sangat Baik \\
2 & RPP & 106 & 145 & Baik \\
3 & Buku Ajar & 71 & 100 & Baik \\
4 & LKS & 68 & 85 & Baik \\
5 & Perangkat Penilaian & 70 & 90 & Baik \\
\hline
\end{tabular}

Tabel 5

Respon SSP oleh Siswa pada Uji Coba Lapangan Awal

\begin{tabular}{cccc}
\hline No & \multicolumn{1}{c}{ SSP } & Skor aktual & Kategori \\
\hline 1 & Buku Ajar & 78 & Sangat Baik \\
2 & LKS & 71 & Baik \\
\hline
\end{tabular}

Berdasarkan Tabel di atas dapat diperoleh informasi penilaian guru terhadap produk SSP mendapatkan kategori sangat baik dan baik. Rinciannya yaitu silabus mendapatkan kategori sangat baik. Sedangkan RPP, bahan ajar, LKS dan perangkat penilaian mendapatkan kategori baik. Penilaian buku ajar oleh siswa mendapatkan kategori sangat baik dan LKS mendapat kategori baik.

Produk SSP yang dikembangkan sangat memungkinkan peserta didik untuk lebih mencintai budaya lokal yang selama ini mulai ditinggalkan. Hal ini karena pembelajaran yang disajikan dirancang dengan sistematis mulai dari silabus hingga perangkat penilaiannya. Komponen silabus yang dikembangkan terdiri dari identitas silabus (satuan pendidikan, kelas/ semester, sub tema, pembelajaran ke-, karakter, alokasi waktu, kompetensi inti) dan 8 kolom meliputi kolom mata pelajaran, kompetensi dasar, indikator, kegiatan pembelajaran, local wisdom, teknik penilaian, bentuk instrumen penilaian, serta sumber dan alat belajar. Silabus yang dikembangkan mencantumkan bentuk local wisdom yang dikembangkan pada silabus dan nantinya akan dikembangkan lebih rinci pada RPP dan dijabarkan sebagai muatan materi pada bahan ajar berbentuk buku ajar. 
RPP yang dikembangkan mencakup enam pembelajaran pada subtema Hidup Rukun dan Teman Bermain. RPP memuat identitas RPP (sekolah, subtema, kelas/ semester, pembelajaran ke-, karakter, dan alokasi waktu), kompetensi inti, kompetensi dasar, indikator, tujuan pembelajaran, materi pokok pembelajaran, pendekatan dan metode pembelajaran, kegiatan pembelajaran, media, alat, dan sumber bahan, serta penilaian. Rumusan indikator disesuaikan dengan kompetensi dasar. Rumusan tujuan disesuaikan dengan indikator dan kompetensi dasar. Alat dan bahan yang dirancang pada RPP disesuaikan dengan indikator dan kebutuhan dalam kegiatan pembelajaran siswa. Sumber belajar yang digunakan adalah buku ajar yang telah dibuat. RPP dilengkapi dengan instrumen penilaian baik kognitif, afektif, maupun psikomotor.

Bahan ajar berbentuk buku ajar terdiri dari cover, kata pengantar, daftar isi, bagian pendahuluan (jaring kompetensi dasar dan indikator, tujuan pembelajaran, materi pokok), bagian inti (uraian materi, kegiatan latihan), penutup (daftar pustaka gambar). Materi ajar dalam buku dikemas semenarik mungkin dengan dengan background lembar kertas berwarna dan menyertakan gambar-gambar atau ilustrasi untuk memperjelas materi dan memotivasi siswa belajar. Hal ini sesuai dengan pendapat Williams (Ariyani \& Nur Wangit, 2016: 127) bahwa bahan ajar yang dirancang dengan menarik dapat memotivasi peserta didik. Dalam buku ajar juga disisipkan kata-kata yang mengandung ajakan agar siswa mengimplementasikan nilai-nilai dari local wisdom.

Contoh salah satu lagu daerah dalam buku ajar yaitu "Gundul-Gundul Pacul". Melalui lagu tersebut siswa diajak untuk tidak sombong. Orang jawa mengartikan Gundul sebagai kepala yang tidak ada rambutnya (plontos). Kepala sendiri oleh orang jawa dianggap sebagai lambang kehormatan. Sementara rambut merupakan mahkota, jadi gundul dapat diartikan sebagai kehormatan tanpa mahkota. Sedangkan Pacul adalah alat yang biasanya digunakan oleh orang untuk bertani. Sehingga makna dari lagu Gundul Gundul Pacul yaitu sebagai seorang pemimpin kita tidak boleh sombong, karena pemimpin sesungguhnya bukan orang yang diberi mahkota tetapi membawa cangkul yang diartikan sebagai rakyat yang harus dihargai dan disejahterakan.

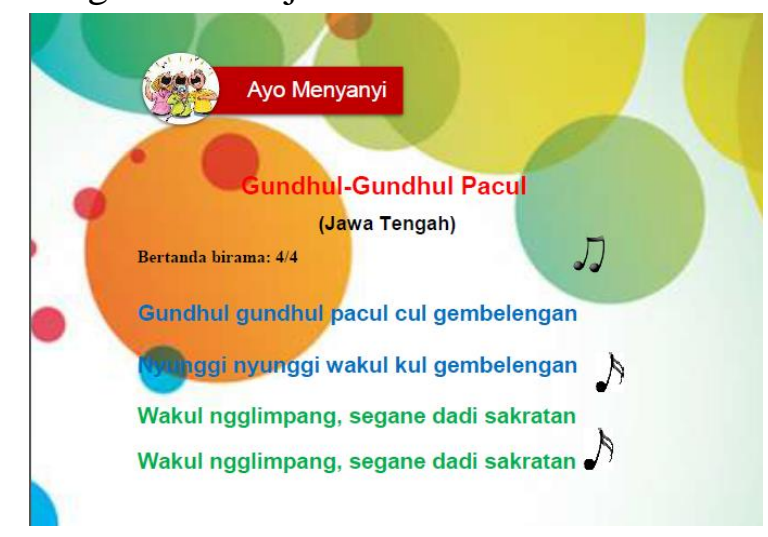

Gambar 1.

Lirik lagu "Gunduh-Gundul Pacul”

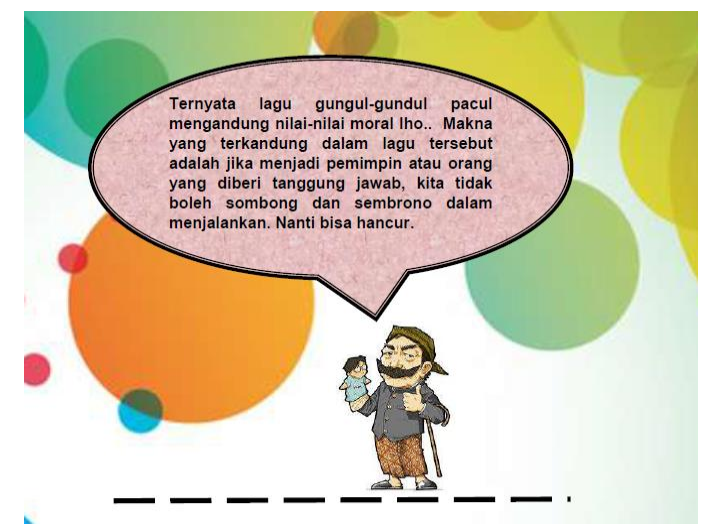

Gambar 2.

Nilai-nilai yang terkandung di dalam lirik lagu "Gunduh-Gundul Pacul"

Local wisdom yang dikembangkan dalam lembar kerja siswa sub tema Hidup Rukun dengan Teman Bermain adalah lagu dolanan, permainan tradisional, tarian daerah, dan alat musik tradisional yang semuanya merupakan local wisdom di wilayah Yogyakarta. Materi dan sumber belajar yang digunakan dalam lembar kerja siswa menggunakan hal-hal yang 
Pengembangan Subject Specific Pedagogy (SSP) Tematik Berbasis Local Wisdom Untuk Membangun Karakter Hormat dan Kepedulian Siswa SD (Amaliyah Ulfah)

dekat dengan kehidupan siswa dan disesuaikan dengan local wisdom yang ada. Tujuan dari pengintegrasikan kearifan lokal dalam lembar kerja siswa selain untuk menanamkan karakter adalah agar siswa mengenal, memahami dan mampu melestarikan kebudayaan yang ada di wilayahnya. Lembar kerja siswa yang dikembangkan dicetak pada kertas berukuran A4 dengan desain yang menarik untuk membangkitkan motivasi belajar peserta didik. Bahasa yang digunakan dalam LKS ini menggunakan bahasa yang sederhana agar mudah dipahami peserta didik serta penulisan dalam lembar kerja siswa dalam penelitian ini menggunakan huruf kecil semua dikarenakan pada kelas awal SD belum dikenalkan penggunaan huruf kapital.

Perangkat penilaian pembelajaran yang dikembangkan memuat komponen penentuan dan penyebaran soal, kisi-kisi soal, soal, kunci jawaban dan rubrik penilaian untuk penanaman karakter. Perangkat penilaian yang dikembangkan juga berbasis local wisdom agar terdapat kesinambungan antar perngkat pembelajaran sehingga pengalaman belajar yang diterima siswa menyeluruh. Perangkat penilaian juga memuat keseluruhan aspek yang dimiliki siswa yaitu aspek afektif, psikomotorik dan kognitif. Tujuannya adalah perangkat penilaian berbasis local wisdom ini dapat benar-benar digunakan oleh pendidik untuk menilai kemampuan siswa secara menyeluruh.

\section{SIMPULAN DAN SARAN}

Produk SSP tematik berbasis local winsdom yang dikembangkan terdiri dari silabus, RPP, Bahan Ajar, LKS, dan perangkat penilaian. Berdasarkan penilaian dari ahli, SSP yang dikembangkan mendapatkan kategori baik. Hasil penilaian guru terhadap SSP berkategori baik. Sedangkan hasil respon siswa masuk dalam kategori sangat baik. Dengan demikian dapat dinyatakan SSP tematik berbasis local wisdom yang dikembangkan layak digunakan dalam pembelajaran.

Pengembangan SSP tematik berbasis local wisdom untuk membangun karakter hormat dan kepedulian siswa sekolah dasar kelas II sudah di uji kevalidan dan kepraktisannya. Akan tetapi belum dilakukan uji keefektifan, oleh karena itu disarankan agar dilakukan uji pada subjek coba yang lebih luas agar diketahui keefektifan dari produk SSP yang telah dikembangkan.

\section{DAFTAR PUSTAKA}

Abidinsyah dan Budimansyah, Dasim. 2012. Internalisasi Nilai Peduli Lingkungan Melalui Pembelajaran Berbasis Kearifan Lokal (Studi di SD Negeri Antasan Besar 7 Banjarmasin). Jurnal Penelitian Pendidikan.13(1).

An-Nisa Apriani dan Muhammad Nur Wangid. 2015. Pengembangan SSP Tematik untuk Menanamkan Kedisiplinan dan Kepedulian Siswa SD Kelas II. Jurnal Prima Edukasia. $3(1), 12-25$.

Battistich, Victor A. 2008. Voices: A Practitioner's Perspective Character Education, Prevention, And Positive Youth Development. Journal of Research in Character Education. 6(81-90).

Darmiyati Zuchdi, dkk. 2014. Pemetaan Implementasi Pendidikan Karakter di SD, Smp, dan SMA Di Kota Yogyakarta. Jurnal Pendidikan Karakter. 4(1).

Krissandi, Apri Damai Sagita dan Rusmawan. 2015. Kendala Guru Sekolah Dasar Dalam Implementasi Kurikulum 2013. Cakrawala Pendidikan, Jurnal Ilmu Pendidikan, 34(3).

Muslih, Masnur. 2011. Pendidikan Karakter Menjawab Tantangan Krisis Multidimensional. 
Jakarta: Bumi Aksara.

Paimun dan Muhsinatun Siasah Masruri. 2014. Pengembangan SSP Tematik untuk Meningkatkan Kejujuran dan Kedisiplinan Siswa Kelas I SD. Jurnal Prima Edukasia, 2(2), 184-208.

Permendiknas No. 8 Tahun 2009 Tentang Program Pendidikan Profesi Guru Pra Jabatan.

Resbiantoro, Gaguk. 2016. Analisis Pedagogical Content Knowledge (PCK) Terhadap Buku Guru SD Kurikulum 2013, dalam Jurnal Scholaria Pendidikan dan Kebudayaan, 6(3), 153-162.

Ristekdikti. 2017. Pedoman Pembukaan Program Studi Pendidikan Profesi Guru di LPTK. Jakarta: Kemristekdikti.

Shulman, L.S. 1986. Those Who Understand: Knowledge Growth In Teaching. Journal Educational Researcher, 15(2),4-14.

Sugiyono. 2015. Metode Penelitian dan Pengembangan. Bandung: Alfabeta.

Sukardjo. 2005. Evaluasi Pembelajaran. Diktat mata kuliah evaluasi pembelajaran. Prodi TP PPs UNY. Tidak diterbitkan.

Sukini. 2012. Pembelajaran Tematik Di Sekolah Dasar Kelas Rendah dan Pelaksanaannya. Klaten. Jurnal Magistra, 24(82).

Tobroni. 2011. Pengembangan Pendidikan Karakter Bangsa Berbasis Kearifan Lokal. Universitas Muhammadiyah Malang, dalam Jurnal Pendidikan Karakter, 14(2).

Van Driel, J. H., Verloop N., \& de Vos, W. 1988. Developing Science Teachers' Pedagogical Content Knowledge, Journal of Research in Science Teaching, 35,673-695.

Warigan. 2012. Pengembangan Karakter Berbasis Kearifan Lokal Hamemayu Hayuning Bawana, Jurnal Pendidikan Karakter, 2(3).

Yenny Anwar, dkk., 2012. Kemampuan Subject Specific Pedagogy Calon Guru Biologi Peserta Program Pendidikan Profesional Guru (PPG) Yang Berlatar Belakang Basic Sains Pra dan Post Workshop. Jurnal Pendidikan IPA Indonesia, 1(2),157-162.

Yusinta Dwi Ariyani dan Muhammad Nur Wangid. 2016. Pengembangan Bahan Ajar Tematik-Integratif Berbasis Nilai Karakter Peduli Lingkungan dan Tanggung Jawab, Jurnal Pendidikan Karakter, 6(1). 